\title{
Peran Guru dalam Optimasi Perkembangan Sikap Disiplin Anak Usia Dini
}

\section{Maimunatul Muna'amah ${ }^{1}$, Siti Masitoh ${ }^{2}$, Sri Setyowati ${ }^{3}$}

1,2,3 Pascasarjana Pendidikan Dasar Konsentrasi PAUD, Universitas Negeri Surabaya, Surabaya, Indonesia

\section{A R T I CLE I N F O}

\section{Article history:}

Received August 08, 2021

Revised August 09, 2021

Accepted October 20, 2021

Available online December 25, 2021

Kata Kunci:

Peran Guru, Sikap Disiplin, Anak Usia Dini

\section{Keywords:}

The Role of The Teacher, Discipline, Early Childhood

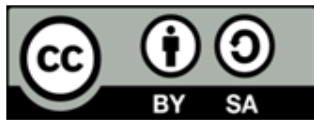

This is an open access article under the CC BY-SA license.

Copyright (C) 2021 by Author. Published by Universitas Pendidikan Ganesha.

\begin{abstract}
A B S T R A K
Sikap disiplin merupakan salah satu karakter yang perlu dikembangkan sejak dini, terutama oleh orangtua. Faktanya masih banyak orangtua yang belum memahami serta tergerak untuk menerapkan perilaku disiplin pada anak-anaknya. Tujuan penelitian ini untuk menganalisis peran guru dalam mengoptimalkan perkembangan sikap disiplin anak usia dini. Penelitian ini menggunakan pendekatan kualitatif dengan jenis penelitian yang digunakan yaitu penelitian kualitatif deskriptif. Pengumpulan data dilakukan dengan menggunakan metode wawancara, observasi dan dokumentasi. Sumber data penelitian kepala sekolah, 2 orang guru dan 13 anak didik. Peneliti sebagai instrumen inti dalam penelitian dan menggunakan instrumen pendukung berupa pedoman wawancara, pedoman observasi. Teknik analisis yang digunakan adalah analisis deskriptif dari Miles \& Huberman dengan menggunakan interactive model. Hasil penelitian menunjukkan bahwa peran guru terhadap sikap disiplin anak yaitu sebagai teladan yang baik bagi anak, guru sebagai pendidik dan pembimbing dengan mengenalkan serta membiasakan anak bersikap disiplin dalam seharihari, dan guru sebagai evaluator. Upaya guru dalam menerapkan sikap disiplin yaitu dengan keteladanan, pembiasaan, dan menggunakan metode reward dan punishment. Faktor yang menjadi penghambat guru dalam menerapkan sikap disiplin anak faktor eksternal yaitu keluarga, lingkungan masyarakat. Faktor internal sikap anak yang hyperaktif atau tantrum. Faktor pendukung yaitu para orangtua yang bersikap mau bekerjasama dengan baik dalam mengambangkan sikap disiplin anaknya. Dapat disimpulkan bahwa guru memiliki peran penting dalam membentuk disiplin siswa di sekolah.
\end{abstract}

\section{A B S T RA C T}

Discipline is one of the characters that need to be developed early, especially by parents. The fact is that there are still many parents who do not understand and are moved to apply disciplined behavior to their children. This study aimed to analyze the teacher's role in optimizing the development of early childhood discipline. This study uses a qualitative approach, with the type of research used being descriptive qualitative research. Data was collected using the interview, observation, and documentation methods. Sources of research data are principals, 2 teachers, and 13 students. Researchers as the core instrument in the study and use supporting instruments in the form of interview guidelines, observation guidelines. The analytical technique used is a descriptive analysis from Miles \& Huberman using an interactive model. The results showed that the teacher's role in the discipline of children is a good role model for children, teachers as educators and mentors by introducing and familiarizing children with discipline in daily life, and teachers as evaluators. The teacher's efforts in implementing a disciplined attitude are by example, habituation, and using the reward and punishment method. Factors that inhibit teachers from applying discipline to children are external factors, namely family and community environment. Internal factors are hyperactive children's attitudes or tantrums. Supporting factors are parents who are willing to cooperate well in developing their children's discipline. It can be concluded that teachers have an important role in shaping school student discipline.

\section{PENDAHULUAN}

Disiplin tentu tidak bisa dipisahkan dengan aturan, bahkan tidak berlebihan jika mengistilahkan aturan adalah salah satu komponen dari sikap disiplin. Disiplin secara sederhana dapat diartikan sebagai 
sikap seorang yang mau belajar dari dan atau suka rela mengikuti seorang pemimpin, pemimpin dalam hal ini adalah orangtua atau guru (Asih \& Sunarso, 2020; Brett et al., 2013; Suyanto, 2018). Dalam konteks pendidikan anak usia dini disiplin merupakan salah satu alat pendidikan, karena dengan disiplin anak dapat belajar sikap mentaati aturan dan membentuk perilaku patuh terhadap norma (Cahyaningrum et al., 2017; Juanda, 2019; Rochimi \& Suismanto, 2019). Lebih spesifik dalam konteks pendidikan anak usia dini disiplin merupakan upaya menjadikan anak agar mempertahankan kesopanan di kelas, menjaga kestabilan dalam kegiatan bersama, serta melatih anak untuk bersikap penuh pengendalian diri (Alvarez et al., 2021; Li et al., 2021; Qazi et al., 2020). Maka sikap disiplin penting dan harus dikembangkan secara optimal sejak dini (Kurniawan et al., 2019; Oktaviani \& Putra, 2021).

Permasalahan yang terjadi saat ini yaitu masih banyak anak yang memiliki sikap disiplin yang kurang (Dewi et al., 2018; Wuryandani, Sapriya, et al., 2014). Permasalahan ini juga ditemukan pada salah satu taman kanak-kanak. RA. Nasyiatul Ulum adalah salah satu lembaga pendidikan anak usia dini berlokasi di desa Montorna kecamatan Pasongsongan. Berdasarkan hasil wawancara dengan kepala sekolah, mengatakan bahwa perkembangan disiplin anak di sekolah tergolong berkembang meski tidak berkembang dengan sangat baik. Hasil observasi juga menunjukkan perilaku disiplin anak dengan memakai seragam yang rapi, membiasakan berdoa sebelum atau sesuai kegiatan belajar, bersikap atau berbicara baik dan sopan, dan tidak terlambat sekolah. Akan tetapi kondisi tersebut tidak secara menyeluruh dan konsisten, beberapa ditemukan anak yang kadang terlambat dan tidak masuk ke sekolah tanpa keterangan, terlambat sekolah, anak memakai seragam kurang rapi, tidak mengikuti kegiatan di kelas dengan tertib dsb. Salah satu guru mengungkapkan salah satu faktornya adalah karena kurangnya didikan kedua orangtua anak perihal sikap disiplin, yang kemungkinan besarnya dilatarbelakangi taraf pendidikan orangtua yang masih rendah, dan atau kesibukan kedua orangtuanya yang bekerja sebagai petani dan beberapa ada yang orangtuanya bekerja di luar negeri.

Kondisi yang terjadi mengenai beberapa faktor yang mempengaruhi ketidakdisplinan anak sejalan dengan hasil penelitian sebelumnya yang disebutkan bahwa anak yang kedua orangtuanya bekerja, berdampak pada keterampilan sosialnya yang belum berkembang sesuai tahapan usianya (Aghniarrahmah et al., 2022; Wuryandani, Maftuh, et al., 2014). Penelitian dalam konteks yang hampir sama pada ibu yang bekerja 24 jam sebagai pedagang diketahui belum tepat dalam memberlakukan aturan, hukuman, maupun penghargaan, serta dalam penanaman disiplin pada anaknya (Nauli \& Meilani, 2019). Pembentukan sikap disiplin anak tidak dapat dibentuk secara instan, harus melalui serangkaian proses pengenalan dan pengembangan sikap yang mengarah pada sikap tertib, taat, patuh terhadap tata tertib serta nilai dan norma, karena disiplin merupakan sikap moral seseorang yang tidak secara otomatis ada pada dirinya sejak lahir, tetapi dibentuk oleh lingkungan melalui pola asuh dan perlakuan orangtua, guru, serta orang-orang dewasa lain di sekitar dirinya (Juwantara, 2019; Kurniawan et al., 2019; Ningsih, 2018). Proses dalam pembentukan sikap disiplin anak ini sebenarnya dipengaruhi oleh dua hal, pertama faktor internal unsur bawaan pribadi anak meliputi kondisi kesehatan fisik dan psikis anak. Kedua faktor eksternal, yaitu unsur yang berasal dari luar pribadi meliputi kondisi keluarga, kondisi lingkungan sekolah, serta kondisi masyarakat di lingkungan tempat tinggalnya (Handayani et al., 2018; Juanda, 2019; Risnawati \& Nuraeni, 2019). Mengenai hambatan yang disebutkan salah satunya karena faktor orangtua yang kurang optimal dalam menanamkan disiplin anaknya, mengindikasikan bahwa sekolah sebagai lingkungan kedua bagi anak memiliki tanggung jawab lebih dalam mengupayakan perkembangan sikap disiplin anak didiknya supaya optimal (Gultom \& Siahaan, 2016; Malik \& Afandi, 2020). Dalam kajian ini lebih khusus merujuk kepada guru, sebagai figur kedua sebagai orangtua kedua anak yang memiliki posisi dan peran penting dalam dunia pendidikan. Lembaga pendidikan merupakan lingkungan yang dituntut untuk mengembangkan kemampuan dan watak serta peradaban bangsa yang bermartabat dan cerdas serta mengembangkan seluruh potensi anak didik seperti tujuan pendidikan nasional pendidikan diharapkan mampu menjadikan manusia yang beriman bertakwa terhadap Tuhan, berbudi pekerti luhur, mandiri, cerdas, kreatif, terampil, berdisiplin dan lain sebagainya (Gürsoy, 2021; Lorenza \& Carter, 2021; Oyedotun, 2020).

Konsep pengembangan disiplin berdasarkan berbagai kajian literasi yang telah disebutkan, jelas bahwa keluarga, sekolah serta masyarakat memiliki peran yang sangat penting (Dewi et al., 2018; Kurniawan et al., 2019; Wuryandani, Sapriya, et al., 2014). Namun kenyataannya masih banyak terjadi di lapangan tidak adanya korelasi yang baik dalam pengembangan disiplin anak, baik dari faktor orangtua dan keluarga terdekat, guru serta masyarakat. Kecenderungan saat ini pendidikan karater termasuk disiplin yang semula menjadi tanggung jawab orangtua selaku pendidik pertama dan utama keluarga kini dialihkan kepada lembaga-lembaga sekolah, pada tingkat permulaan fungsi ibu sebagian sudah dialikan kepada guru pra sekolah yang sejatinya adalah tugas keluarga. Pandangan serupa juga dijelaskan bahwa para orangtua banyak yang bersikap kurang peduli terhadap proses perkembangan pendidikan anaknya, termasuk kurang memperhatikan dalam hal penanaman disiplin dalam kehidupan sehari-hari. Temuan penelitian sebelumnya menyatakan bahwa guru memiliki peran yang sangat penting dalam membentuk karakter 
siswa (Novianti, 2017; Risnawati \& Nuraeni, 2019; Wuryani \& Yamtinah, 2018). Temuan penelitian lainnya juga menyatakan bahwa guru berperan penting dalam membentuk sikap displin pada siswa disekolah (Arsa et al., 2017; Dewi et al., 2018; Wuryandani, Sapriya, et al., 2014). Tujuan penelitian ini yaitu menganalisis peran guru pendidikan anak usia dini dalam optimalisasi perkembangan sikap disiplin anak, apa saja peran yang dijalankan, upaya yang dilakukan serta untuk mengetetahui secara lebih konkrit faktor-faktor yang mempegaruhi optimalisasi perkembangan sikap disiplin anak di sekolah. Diharapkan bisa menjadi bahan referensi serta evaluasi tentang pengembangan sikap disiplin anak bagi guru dan ataupun orangtua.

\section{METODE}

Penelitian ini menggunakan pendekatan kualitatif. Jenis penelitian yang digunakan yaitu penelitian kualitatif deskriptif. Kualitatif deskriptif sebagai penelitian yang bermaksud memahami fenomena tentang apa yang dialami oleh subjek penelitian misalnya perilaku, persepsi, motivasi, tindakan, dan lain-lain secara holistik dan dengan cara deskripsi dalam bentuk kata-kata dengan memanfaatkan berbagai metode ilmiah (Yusuf, 2017). Pendekatan kualitatif deskriptif dianggap tepat digunakan, karena peneliti melakukan penelitian dengan latar belakang alamiah dan menyeluruh sehinggga dapat menggambarkan keadaan yang sebenarnya mengenai peran guru dalam menerapkan sikap disiplin anak di RA. Nasyiatul Ulum Montorna Pasongsongan dengan peneliti sendiri sebagai instrumen kunci penelitian. Penggunaan data deskriptif artinya data yang dikumpulkan dalam penelitian ini adalah kumpulan data secara ilmiah mengenai situasi, tata cara yang berlaku situasi, berlangsung mengenai peran guru di RA. Nasyiatul Ulum Montorna Pasongsongan. Data-data tersebut kemudian dianalisis menggunakan teori-teori yang relevan. Sumber data dalam penelitian ini adalah kepala sekolah, 2 guru, dan 13 anak didik RA. Nasyiatul Ulum. Teknik pengumpulan data yang digunakan oleh peneliti dalam penelitian ini adalah yaitu dengan wawancara, observasi, dan dokumentasi dengan menyertakan kisi-kisi penelitian.

Tabel 1. Kisi-kisi instrumen wawawancara

\begin{tabular}{|c|c|}
\hline No & Indikator Wawancara \\
\hline 1 & Perkembangan sikap disiplin anak \\
\hline 2 & Metode yang digunakan dalam upaya menerapkan sikap disiplin anak \\
\hline 3 & Kegiatan yang diterapkan dalam pengembangan sikap disipin anak \\
\hline 4 & $\begin{array}{l}\text { Faktor-faktor yang menjadi hambatan dan dukungan yang dihadapi guru dalam menerapkan } \\
\text { sikap disiplin }\end{array}$ \\
\hline 5 & $\begin{array}{l}\text { Upaya yang dilaksanakan dalam menghadapi hambatan penerapan disiplin anak di RA. Nasyiatul } \\
\text { Ulum Montorna Pasongsongan }\end{array}$ \\
\hline 6 & Peran guru dalam guru dalam menerapkansikap disiplin anak \\
\hline 7 & Proses monitoring/pengawasan guru terhadap sikap disiplin anak \\
\hline
\end{tabular}

Teknik analisis data penelitian ini adalah analisis deskriptif, yaitu dengan mendeskripsikan dan memaknai data dari masing-masing komponen yang diteliti, teknik analisis yang digunakan menggunakan interactive model, yang terdiri dari tiga alur (tahapan) kegiatan yaitu: reduksi data, penyajian data, penarikan kesimpulan/verifikasi (Miles, \& Huberman, 2014). Dalam menguji keabsahan data peneliti menggunakan teknik triangulasi, yaitu pemeriksaan keabsahan data yang memanfaatkan sesuatu yang lain dluar data untuk keperluan pengecekan atau sebagai pembanding terhadap data tersebut dan teknik triangulasi yang paling banyak digunakan adalah dengan pemeriksaan melalui sumber yang lainnya. Peneliti menggunakan triangulasi sumber adalah membandingkan, mengecek ulang derajat kepercayaan suatu informasi yang diperoleh melalui melalui sumber yang berbeda. Dalam penelitian ini, peneliti melakukan uji perbandingan data yang diperoleh dari hasil observasi dengan wawancara, hasil wawancara dengan dokumetasi, dan lainnya menyangkut data dari berbagai sumber yang diperoleh. Peneliti juga melakukan triangulasi metode yaitu dengan jalan membandingkan data atau informasi dengan cara yang berbeda. Untuk memperoleh kebenaran data secara akurat menggunakan wawancara dan observasi untuk mengecek kebenarannya dan melalui berbagai perspektif dari subjek atau informan hal ini dilakukan apabila data yang diperoleh diragukan kebenarannya.

\section{HASIL DAN PEMBAHASAN}

Hasil

Berdasarkan pada analisis yang sudah dilakukan di lapangan, maka dapat dinyatakan bahwa peran guru RA. Nasyiatul Ulum Montorna dalam optimalisasi perkembangan sikap disiplin anak didiknya yaitu dengan guru menjadi teladan yang baik anak, Hal tersebut terlihat dari penemuan di lapangan ketika para 
guru berperilaku dan memberi contoh hal-hal yang mencerminkan sikap disiplin pada anak contohnya guru yang selalu datang tepat waktu ke sekolah, selalu berpakaian rapi dan sopan, bertutur kata yang baik, serta guru mencontohkan meletakkan sepatu dan atau membuang sampah ke tempatnya. Hal tersebut menjadi cerminan dari sikap guru sebagai seorang teladan dalam berdisiplin bagi anak didiknya. Guru juga berperan sebagai pendidik dan pembimbing, dengan mengajarkan kepada anak untuk selalu berperilaku disiplin, membiasakan anak belajar disiplin dengan tepat waktu tiba di sekolah, antre dengan tertib ketika cuci tangan, meletakkan barang dan mainanya dengan rapi, serta mengarahkan agar tertib saat kegiatan pembelajaran berlangsung dan tidak mengganggu. Selain itu, guru sebagai evaluator yaitu guru melaksakan evaluasi terhadap perkembangan sikap disipin anak di sekolah, guru akan mengamati dan mencatat proses perkembangan anak termasuk mengamati kesulitan dan kendala yang dialami anak dalam perkembangan sikap disiplinnya. Peran yang dijalankan guru menunjukkan bahwa dalam mengembangkan karakter disiplin anak usia dini membutuhkan pendampingan intensif dari orang terdekat di lingkungannya. Terutama guru sebagai seseorang yang bertanggung jawab penuh dalam penjaminan mutu dan kualitas keilmuan dan karakter anak didiknya. Sebagai lingkungan kedua bagi anak sekolah selayaknya menjadi tempat anak belajar dan mengembangkan dirinya dengan baik. Peran guru sebagai teladan tidak lain karena segala hal yang dilakukan guru akan mendapat perhatian lebih dari peserta didik maupun orangorang di sekitarnya, maka seharusnya guru dapat menjadi contoh atau model yang paling utama di sekolah selalu mengupayakan dengan membiasakan hal-hal yang positif pada diri anak. Hal tersebut sejalan dengan hasil penelitian sebelumnya, mengenai peran guru sebagai sangat tinggi dalam mendukung sikap disiplin belajar pada siswa. Guru memiliki peran yang penting dalam sikap disiplin belajar siswa, karena guru ialah sosok pengganti orang tua ketika siswa berada dalam sekolah. Seluruh perilaku guru akan menjadi contoh atau teladan bagi siswa dalam perilaku disiplin. Peran guru yang tinggi dalam mendidik serta membimbing dan menjadi teladan dalam sikap disiplin, maka akan mewujudkan sikap disiplin belajar yang tinggi pula pada diri siswa.

Dari berbagai hasil tersebut, jelas bahwa guru berperan sebagai teladan yang baik bagi anak didik dalam berdisiplin dengan menjadi panutan dan contoh dalam berperilaku yang seharusnya misal sikap guru dalam berbicara, kebisaan guru dalam membuang sampah ke tempatnya dan berusaha selalu tepat waktu saat di sekolah menjadi cerminan yang baik bagi anak, ditambah dengan pemberian bimbingan dan arahan tentang bagaimana cara bersikap dalam berdisiplin, yang dikalakukan secara terus menerus sehingga menjadi kebiasaan. Selain itu tindakan mengevaluasi menjadi langkah yang cukup efektif yang dapat dilakukan guru di sekolah dalam mengoptimalisasi perkembangan sikap disiplin anak usia dini. Faktor yang menjadi penghambat berdasarkan temuan dilapangan, yaitu faktor eksternal berupa keluarga yang kurang peduli dan mengajarkan anaknya dalam berdisiplin di rumah, lingkungan masyarakat juga dalam kasus ini ditemukan bahwa kurang bersinergi dalam memberikan contoh sikap disiplin, banyak ditemukan yang masih meembuang sampah sembarangan, berbicara kurang sopan, tidak tertib berkendara dan lainnya. Sedangkan faktor internal berupa sikap anak yang hyperaktif atau tantrum. Faktor pendukungnya yaitu para orangtua yang bersikap mau bekerjasama dengan baik dalam mengembangkan sikap disiplin anaknya.

Fakta bahwa para orangtua bersikap abai dan kurang membiasakan anak berdisiplin di rumah menjadikan tersebut kurang singkron dengan pendidikan yang diajarkan di sekolah, karena idealnya lingkungan keluarga merupakan salah satu kunci keberhasilan penanaman pendidikan disiplin anak sejak dini, orangtua sebagai pendidik yang pertama dan utama selayaknya memberikan dasar-dasar yang tepat. Sehingga kondisi ini menjadi kendala dalam menerapkan sikap disiplin anak yang cukup dikeluhkan dan menjadi problematika tersendiri bagi guru. Kondisi yang dialami di sekolah di RA. Nasyiatul Ulum Montorna Pasongsongan faktor internal yang berasal dari anak juga menjadi masalah dan hambatan, beberapa anak yang kurang stabil mengelola emosinya, bersifat hyperaktif hingga tantrum merupakan salah satu kendala bagi guru. Selain menghambat terhadap perkembangan anak, kondisi ini juga mempengaruhi anak-anak yang lain dengan mengganggu konsentrasi dan kegiatan yang berlangsung. Anak-anak lain merasa terganggu, guru juga harus mengajar dengan perhatian ekstra. Kondisi tersebut menunjukkan bahwa Keadaan psikis anak akan juga sangat mempengaruhi terhadap perilaku anak, termasuk sikap disiplin anak. Faktor pendukung yaitu para orangtua mau bekerjasama dengan baik dalam mengembangkan sikap disiplin anaknya. kondisi yang dialami selaras dengan hasil penelitian tentang peran penting orangtua dalam menanamkan disiplin anak terbukti bahwa Orang tua merupakan kunci utama dalam penerapan kedisiplinan anak sejak usia dini. Orang tua memiliki peranan yang cukup penting dalam penanaman pendidikan dalam lingkungan keluarga, dan tidak dapat diberikan dan digantikan di lembaga pendidikan. Idealnya sebuah keluarga yang baik adalah keluarga yang mengajarkan dan membina anak bersikap disiplin dengan membiasakan anak menerapkan norma-norma sosial, moral agama yang dianutnya. Dalam lingkungan keluarga orangtua memegang peran penting bagi perkembangan disiplin dari anggota-anggota lain dalam keluarga. Sehingga kondisi yang dialami dalam lembaga pendidikan apabila keluarga kurang 
mendukung maka secara tidak langsung akan turut mengganggu terhadap proses pendidikan yang dilakukan, dan bisa menjadi penyebab kurang optimalnya tumbuh kembang anak.

\section{Pembahasan}

Dalam mendidik sikap disiplin pada anak usia dini para guru sangat menyadari bahwa akan membutuhkan beberapa upaya agar efektif, latar belakang keluarga, sifat dan karakter anak yang berbeda maka akan membutuhkan solusi yang tidak seragam (Aditya et al., 2019; Kurniawan et al., 2019; Permatasari et al., 2021). Berdasarkan hasil wawancara serta observasi yang dilakukan upaya-upaya guru di sekolah yaitu dengan keteladanan, guru meyakini bahwa pada masa pra sekolah dapat dikatakan periode anak paling banyak meniru tingkah laku dari orang-orang lingkungannya. Hal ini yang menyebabkan guru selalu berupaya menjalankan sikap disiplin yang baik di sekolah dengan datang tepat waktu bahkan lebih pagi dari anak didiknya, tidak meletakkan sepatu sembarangan, tidak membuang sampah sembarangan, dan lain sebagainya (Fitriani, 2019; Radyuli \& Rahmat, 2017; Wuryandani, Maftuh, et al., 2014). Guru juga menggunakan metode pembiasaan, pembiasaan ini hampir dilakukan dalam banyak kegiatan di sekolah, seperti membiasakan anak rapi menggunakan seragam, membiasakan anak meletakkan alat belajar dan mainannya sesuai tempatnya, membiasakan anak mengerjakan tugas dengan baik, membiasakan anak tertib di kelas, dan banyak hal lain.

Guru juga menerapkan metode reward dan punishment, reward (pujian) dan punishment (hukuman), dalam konteks ini hukuman yang dilakukan dalam kategori mendidik, dan tidak mengandung unsur kekerasan atau pelecehan baik secara mental atau fisik (Arsa et al., 2017; Pratiwi, 2020; Sapulette \& Wardana, 2016). Bentuk reward yang diberikan guru yaitu berupa pujian, atau apreasi dengan tepuk tangan saat anak dapat secara disiplin menyelesaikan tugas dengan baik (Kraft \& Papay, 2014; Rochimi \& Suismanto, 2019). Punishment dari guru dilakukan apabila terdapat anak yang tidak tertib, misal anak mengganggu kegiatan pembelajaran, tidak mengerjakan tugas, tidak mau antri dan lain sebagainya, maka guru akan memberikan hukuman dalam bentuk teguran, atau menunjukkan sikap kecewa pada anak (Ramdan \& Fauziah, 2019; Santosa \& Andrean, 2021; Wahyono et al., 2020). Terkadang guru juga menegur dalam bentuk konsekuensi misal anak akan pulang giliran paling akhir apabila anak tidak mau tertib di kelas, atau diminta membuang sampah apabila anak diketahui membuang sampah tidak pada tempatnya.

Berbagai upaya yang dilakukan guru selaras dengan paparan data penelitian mengenai strategi pembentukan karakter siswa dari perspektif strategi guru dilakukan melalui contoh teladan secara langsung setiap hari, pembiasaan melalui keterlibatan langsung melakukannya dalam pembelajaran dan sentuhan kalbu dengan kata-kata hikmah (Pitaloka et al., 2021; Surahman \& Mukminan, 2017). Mengenai upaya-upaya yang diterapkan guru dipandang efektif jika mengacu pada karakteristik anak usia dini. Seorang anak dapat belajar dan merespon hal-hal baru dengan pengamatan terhadap perilaku contoh dari orang-orang sekitarnya, misanya meniru guru atau orang tua (Lumban Gaol \& Siburian, 2018; Sufiati \& Afifah, 2019; Utari et al., 2020). Jika seorang guru menghendaki anak didiknya berperilaku dan bersikap sesuai dengan nilai-nilai budaya dan karakter bangsa yang diharapkan maka guru adalah yang pertama memberikan contohnya. Temuan penelitian sebelumnya juga menyatakan bahwa upaya guru menanamkan nilai-nilai kedisplinan dengan menggunakan metode keteladanan, terbukti cukup efektif dalam menanamkan nilai-nilai disiplin anak didiknya (Rochimi \& Suismanto, 2019). Temuan penelitian lainnya juga menyatakan bahwa guru harus memberikan contoh yang baik dalam upaya penanaman nilai-nilai displin pada siswa (Kurniawan et al., 2019; Rochimi \& Suismanto, 2019). Metode ini sangat praktis dalam pembinaan dan pembentukan karakter anak usia dini dalam meningkatkan pembiasaan-pembiasaan dalam melaksanakan suatu kegiatan di sekolah. Peran guru dalam upaya optimalisasi perkembangan sikap disiplin anak yaitu dengan guru berperan sebagai teladan dengan memberikan contoh sikap disiplin yang baik anak. Guru berperan sebagai pendidik dengan membimbing dan membiasakan anak agar tertib aturan dan melaksanakan kegiatan di sekolah, evaluator, melakukan evaluasi perkembangan sikap disipin anak dan menilai sejauh mana proses perkembangan sikap disiplin anak.

\section{SIMPULAN}

Upaya-upaya yang diterapkan guru yaitu dengan keteladanan, pembiasaan, menggunakan metode reward dan punishment. Beberapa faktor penghambat dalam menerapkan disiplin ada faktor eksternal berupa kurangnya kepedulian dan pehamaman para orangtua dalam menanamkan disiplin anaknya dan lingkungan masyarakat sekitar anak yang juga kurang disiplin. Ada pula dipengaruhi faktor internal anak yang bersikap hyperaktif atau tantrum. Faktor pendukung yaitu para orangtua yang bersikap mau bekerjasama dengan baik dalam mengambangkan sikap disiplin anaknya. 


\section{DAFTAR RUJUKAN}

Aditya, I. K. D., Sumantri, M., \& Astawan, I. G. (2019). Pengaruh Model Pembelajaran Learning Cycle (5e) Berbasis Kearifan Lokal Terhadap Sikap Disiplin Belajar Dan Hasil Belajar Ipa Siswa Kelas Iv Sd Gugus V Kecamatan Sukasada. Jurnal Pendidikan Multikultural Indonesia, 2(1). https://doi.org/10.23887/jpmu.v2i1.20792.

Aghniarrahmah, C., Fridani, L., \& Supena, A. (2022). Perkembangan Kemandirian dan Keterampilan Sosial Anak Usia 5-6 Tahun dalam Pengasuhan Dual Career Family. 6(1), 389-400. https://doi.org/10.31004/obsesi.v6i1.1319.

Alvarez, A., Teeters, L. P., Hamm-Rodríguez, M., \& Dimidjian, S. (2021). Understanding children's funds of identity as learners through multimodal self-expressions in Mexico City. Learning, Culture and Social Interaction, 29. https://doi.org/10.1016/j.lcsi.2021.100513.

Arsa, I. G. A. S. A., Sujana, I. W., \& Wiarta, I. W. (2017). Korelasi Antara Disiplin Dalam Belajar Dengan Kompetensi Pengetahuan IPS Siswa Kelas Iv Sd Gugus 1 Kecamatan Mengwi Tahun Pelajaran 2016/2017. Journal of Education Technology, 1(3), 156. https://doi.org/10.23887/jet.v1i3.12499.

Asih, P., \& Sunarso, A. (2020). Implementation of Character Education to Improve the Students Discipline Through Habituation of Nadzam Asmaul Husna Recitation at Grade IV. Elementary School Teacher, 3(1). https://doi.org/10.15294/est.v3i1.28035.

Brett, J., Brimhall, J., Healey, D., Pfeifer, J., \& Prenguber, M. (2013). Competencies for Public Health and Interprofessional Education in Accreditation Standards of Complementary and Alternative Medicine Disciplines. EXPLORE, 9(5). https://doi.org/10.1016/j.explore.2013.06.001.

Cahyaningrum, E. S., Sudaryanti, S., \& Purwanto, N. A. (2017). Pengembangan Nilai-Nilai Karakter Anak Usia Dini Melalui Pembiasaan Dan Keteladanan. Jurnal Pendidikan Anak, 6(2), 203-213. https://doi.org/10.21831/jpa.v6i2.17707.

Dewi, K. M. S., Suwatra, I. W., \& Suarjana, M. (2018). Kontribusi Disiplin Belajar dan Motivasi Berprestasi Terhadap Hasil Belajar Matematika. Jurnal Penelitian Dan Pengembangan Pendidikan, 2(2), 152. https://doi.org/10.23887/jppp.v2i2.15397.

Fitriani, S. (2019). Pendidikan Karakter Sebagai Upaya Menciptakan Akhlak Mulia Siswa Sekolah Dasar. ELSE (Elementary School Education Journal) : Jurnal Pendidikan Dan Pembelajaran Sekolah Dasar, 3(2), 229-238. https://doi.org/10.30651/else.v3i2.3011.

Gultom, L., \& Siahaan, M. F. (2016). Penerapan Reward dan Konsekuensi untuk Meningkatkan Kedisiplinan Siswa Kelas II SD Sekolah Kristen ABC [The Implementation of Rewards and Consequences to Improve Students' Discipline in Grade II of Christian School ABC]. Polyglot: Jurnal Ilmiah, 12(2). https://doi.org/10.19166/pji.v12i2.368.

Gürsoy, G. (2021). Digital storytelling: Developing 21st century skills in science education. European Journal of Educational Research, 10(1), 97-113. https://doi.org/10.12973/EU-JER.10.1.97.

Handayani, Purwadi, \& Prasetiyawati. (2018). Upaya Meningkatkan Kecerdasan Musikal Anak Usia Dini Melalui Permainan Alat Musik Tradisional Angklung Pada Anak Kelompok B RA Karakter Semarang. PAUDIA: Jurnal Penelitian Dalam Bidang Pendidikan Anak Usia Dini, 7(2). https://doi.org/10.26877/paudia.v7i2.3272.

Juanda, J. (2019). Pendidikan Karakter Anak Usia Dini melalui Sastra Klasik Fabel Versi Daring. Jurnal Obsesi : Jurnal Pendidikan Anak Usia Dini, 3(1), 39. https://doi.org/10.31004/obsesi.v3i1.126.

Juwantara, R. A. (2019). Analisis Teori Perkembangan Kognitif Piaget Pada Tahap Anak Usia Operasional Konkret 7-12 Tahun dalam Pembelajaran Matematika. Jurnal Ilmiah Pendidikan Guru Madrasah Ibtidaiyah, 9(1), 27-34. https://doi.org/10.18592/aladzkapgmi.v9i1.3011.

Kraft, M. A., \& Papay, J. P. (2014). Can professional environments in schools promote teacher development? Explaining heterogeneity in returns to teaching experience. Educational Evaluation and Policy Analysis, 36, 476-500. https://doi.org/10.3102/0162373713519496.

Kurniawan, D. A., Astalini, A., Kurniawan, N., \& Pathoni, H. (2019). Analisis korelasi sikap siswa dan disiplin siswa terhadap IPA pada Siswa SMP Provinsi Jambi. Jurnal Pendidikan Fisika Dan Keilmuan (JPFK). https://doi.org/10.25273/jpfk.v5i2.5014.

Li, Y., Wang, Y., Chen, X., Li, S., \& Zhang, L. (2021). Do children know that fantastic events in television programs are not real? Cognitive Development, 58. https://doi.org/10.1016/j.cogdev.2021.101020.

Lorenza, L., \& Carter, D. (2021). International Journal of Educational Research Open Emergency online teaching during COVID-19: A case study of Australian tertiary students in teacher education and creative arts. International Journal of Educational Research Open, 2-2(May), 100057. https://doi.org/10.1016/j.ijedro.2021.100057.

Lumban Gaol, N. T., \& Siburian, P. (2018). Peran Kepala Sekolah Dalam Meningkatkan Kinerja Guru. Kelola: Jurnal Manajemen Pendidikan, 5(1), 66-73. https://doi.org/10.24246/j.jk.2018.v5.i1.p66-73.

Malik, A., \& Afandi, M. (2020). Peningkatan Disiplin Dan Prestasi Belajar Pendidikan Agama Islam Melalui 
Model Pembelajaran Quantum Teaching Kelas Vii Mts Nu Al Ishlah Binabaru. Jurnal Ilmiah Pendidikan Dasar, 7(1). https://doi.org/10.30659/pendas.7.1.60-67.

Miles, Matthew B \& Huberman, A. M. (2014). Analisis Data Kuaitatif: buku Sumber metode-metode baru. UIPress.

Nauli, V. A., \& Meilani, S. M. (2019). Jurnal Obsesi : Jurnal Pendidikan Anak Usia Dini Peran Ibu Pedagang Pasar 24 Jam Terhadap Perkembangan Moral Anak ( Penelitian Studi Kasus di Kota Bekasi ). 3(1), 241-253. https://doi.org/10.31004/obsesi.v3i1.179.

Ningsih, Y. (2018). Penilaian Sikap Sosial Pada Anak Berkebutuhan Khusus Di Slb Negeri 2 Yogyakarta. Jurnal Bimbingan Dan Konseling Islam, 08(02), 208-215. https://doi.org/10.29080\%2Fjbki.v8i2.85.

Novianti, N. (2017). Teaching character education to college students using bildungsromans. International Journal of Instruction, 10(4), 255-272. https://doi.org/10.12973/iji.2017.10415a.

Oktaviani, N. K. W., \& Putra, M. (2021). Motivasi dan Disiplin Kerja Terhadap Kinerja Guru di Sekolah Dasar. Jurnal Imiah Pendidikan Dan Pembelajaran, 5(2), 294. https://doi.org/10.23887/jipp.v5i2.35146.

Oyedotun, T. D. (2020). Sudden change of pedagogy in education driven by COVID-19: Perspectives and evaluation from a developing country. Research in Globalization, 2(June), 100029. https://doi.org/10.1016/j.resglo.2020.100029.

Permatasari, N. A., Setiawan, D., \& Kironoratri, L. (2021). Model Penanaman Karakter Disiplin Siswa Sekolah Dasar pada Masa Pembelajaran Daring. Educatif: Jurnal Ilmu Pendidikan, 3(6), 3758-3768. https://doi.org/10.31004/edukatif.v3i6.1303.

Pitaloka, D. L., Dimyati, D., \& Edi, P. (2021). Peran Guru dalam Menanamkan Nilai Toleransi pada Anak Usia Dini di Indonesia. Jurnal Obsesi: Jurnal Pendidikan Anak Usia Dini, 5(2), 1696-1705. https://doi.org/10.31004/obsesi.v5i2.972.

Pratiwi, S. I. (2020). Pengaruh Ekstrakurikuler Pramuka Terhadap Karakter Disiplin Siswa SD. Edukatif: Jurnal Ilmu Pendidikan, 2(1), 62-70. https: //doi.org/10.31004/edukatif.v2i1.90.

Qazi, A., Naseer, K., Qazi, J., Alsalman, H., Naseem, U., Yang, S., Hardaker, G., \& Gumaei, A. (2020). Children and Youth Services Review Conventional to online education during COVID-19 pandemic: Do develop and underdeveloped nations cope alike. Children and Youth Services Review, 119(October), 105582. https://doi.org/10.1016/j.childyouth.2020.105582.

Radyuli, P., \& Rahmat, V. (2017). Korelasi Disiplin Belajar dan Kreativitas Belajar Terhadap Minat Belajar Teknologi Informasi dan Komunikasi ( TIK ). Jurnal Pendidikan Dan Teknologi Informasi, 4(2), 262271. https://doi.org/10.23887/jipp.v3i3.21834.

Ramdan, A. Y., \& Fauziah, P. Y. (2019). Peran orang tua dan guru dalam mengembangkan nilai-nilai karakter anak usia sekolah dasar. Jurnal Pendidikan Dasar Dan Pembelajaran, 9(2), 100. https://doi.org/10.25273/pe.v9i2.4501.

Risnawati, A., \& Nuraeni, L. (2019). Meningkatkan Kemampuan Berbahasa Sunda Anak Usia Dini Melalui Kegiatan Rebo Nyunda Di Pendidikan Anak Usia Dini. CERIA (Cerdas Energik Responsif Inovatif Adaptif), 2(5). https://doi.org/10.22460/ceria.v2i5.p243-250.

Rochimi, I. F., \& Suismanto, S. (2019). Upaya Guru Menanamkan Nilai-nilai Kedisplinan pada Anak Usia Dini. Golden Age: Jurnal Ilmiah Tumbuh Kembang Anak Usia Dini, 3(4), 231-246. https://doi.org/10.14421/jga.2018.34-02.

Santosa, S., \& Andrean, S. (2021). Pengembangan dan Pembinaan Karakter Siswa dengan Mengoptimalkan Peran Guru Sebagai Contextual Idol di Sekolah Dasar. Jurnal Basicedu, 5(2), 952-957. https://doi.org/10.31004/basicedu.v5i2.849.

Sapulette, M. S., \& Wardana, A. (2016). Peningkatan Karakter Siswa Kelas IV SD Negeri 16 Ambon Melalui Pembelajaran PPKn Dengan Media Cerita Rakyat. Harmoni Sosial: Jurnal Pendidikan IPS, 3(2), 150165. https://doi.org/10.21831/hsjpi.v3i2.11922.

Sufiati, V., \& Afifah, S. N. (2019). Peran perencanaan pembelajaran untuk performance mengajar guru pendidikan anak usia dini. Jurnal Pendidikan Anak, 8(1), 48-53. https://doi.org/10.21831/jpa.v8i1.26609.

Surahman, E., \& Mukminan. (2017). Peran guru IPS sebagai pendidik dan pengajar dalam meningkatkan sikap sosial dan tanggung jawab sosial siswa SMP. Harmoni Sosial: Jurnal Pendidikan IPS, 4(1), 113. https://doi.org/10.21831/hsjpi.v4i1.8660.

Suyanto, S. (2018). Competence and discipline on work motivation and the implication on working performance. European Research Studies Journal, 21(1), 570-587. https://doi.org/10.35808/ersj/971.

Utari, L., Kurniawan, \& Fathurrochman, I. (2020). Peran Guru Pendidikan Agama Islam dalam Membina Akhlak Peserta Didik Autis. JOEAI (Journal of Education and Instruction), 3(1), 75-89. https://doi.org/10.31539/joeai.v3i1.1304. 
Wahyono, P., Husamah, H., \& Budi, A. S. (2020). Guru profesional di masa pandemi COVID-19: Review implementasi, tantangan, dan solusi pembelajaran daring. Jurnal Pendidikan Profesi Guru, 1(1), 5165. https://doi.org/10.22219/jppg.v1i1.12462.

Wuryandani, Sapriya, \& Budimansyah. (2014). Pendidikan Karakter Disiplin Di Sekolah Dasar. Cakrawala Pendidikan, 33(2), 286-295. https://doi.org/10.21831/cp.v2i2.2168.

Wuryandani, W., Maftuh, B., Sapriya, \& Budimansyah, D. (2014). Pendidikan Karakter Disiplin Di Sekolah Dasar. Jurnal Cakrawala Pendidikan, 2(2), 286-295. https://doi.org/10.21831/cp.v2i2.2168.

Wuryani, M. T., \& Yamtinah, S. (2018). Textbooks Thematic Based Character Education on Thematic Learning Primary School: An Influence. International Journal of Educational Methodology, 4(2), 7581. https://doi.org/10.12973/ijem.4.2.75.

Yusuf, A. M. (2017). Metode Penelitian Kuantitatif, Kualitatif, \& Penelitian Gabugnan (Pertama). Kencana. 